\title{
Hematological changes in patients with COVID-19 (Review)
}

\author{
JIEYU YE $^{1 *}$, YINGYING JIAO $^{1 *}$, YUJIAO ZHANG ${ }^{1}$, ZONGPENG LI $^{1}$, \\ XIAOYUAN ZENG ${ }^{1}$, HUIXIA DENG ${ }^{2}$ and MO YANG $^{3}$ \\ ${ }^{1}$ Department of Hematology, Nanfang Hospital, Southern Medical University; \\ ${ }^{2}$ Department of Paediatrics, Nanfang Hospital, Southern Medical University, \\ Guangzhou, Guangdong 510515; ${ }^{3}$ The Research Center of Seventh Affiliated Hospital, \\ Sun Yat-sen University, Shenzhen, Guangdong 518107, P.R. China
}

Received May 11, 2020; Accepted July 22, 2020

DOI: $10.3892 / \mathrm{mmr} .2020 .11581$

\begin{abstract}
In December 2019, an emergence of pneumonia was detected in patients infected with a novel coronavirus (CoV) in Wuhan (Hubei, China). The International Committee on Taxonomy of Viruses named the virus severe acute respiratory syndrome-CoV-2 and the disease $\mathrm{CoV}$ disease-19 (COVID-19). Patients with COVID-19 present with symptoms associated with respiratory system dysfunction and hematological changes, including lymphopenia, thrombocytopenia and coagulation disorders. However, to the best of our knowledge, the pathogenesis of COVID-19 remains unclear. Therefore, understanding the mechanisms underlying the hematological changes that manifest during COVID-19 may aid in the development of treatments and may improve patient prognosis.
\end{abstract}

\section{Contents}

1. Introduction

2. Hematological changes in patients with COVID-19

3. Possible mechanisms of lymphopenia and thrombocytopenia in patients with COVID-19

4. Possible mechanisms involved in coagulation disorders in patients with COVID-19

5. Potential treatments

6. Conclusions

Correspondence to: Professor Mo Yang, The Research Center of Seventh Affiliated Hospital, Sun Yat-sen University, 628 Zhenyuan Road, Guangming, Shenzhen, Guangdong 518107, P.R. China

E-mail: yangm1091@126.com

${ }^{*}$ Contributed equally

Key words: coronavirus disease-19, lymphopenia, thrombocytopenia, cytokine storm, coagulation disorder

\section{Introduction}

In December 2019, symptoms associated with pneumonia in patients infected with a novel coronavirus $(\mathrm{CoV})$ emerged in Wuhan (Hubei, China) (1). The virus was classified as a new member of the human $\mathrm{CoV}(\mathrm{HCoV})$ family and named severe acute respiratory syndrome (SARS)-CoV-2. The disease caused by SARS-CoV-2 was termed CoV disease-19 (COVID-19) $(2,3)$. SARS-CoV-2 is a highly contagious viral particle that has spread across the Chinese and global populations within a few months (4). The seven types of $\mathrm{CoV}$ are listed in Table I and include two $\alpha$-CoVs (HCoV-NL63 and HCoV-229E) and four $\beta$-CoVs [HCoV-OC43, HCoVHKU1, SARS-CoV and Middle East respiratory syndrome (MERS)-CoV] (5). SARS-CoV-2 is the seventh member of the family of enveloped RNA CoVs. A recent analysis (6) indicated that SARS-CoV-2 is divergent from SARS-CoV and MERS-CoV, but shares $>85 \%$ homology with SARS-CoV. SARS-CoV-2 enters cells by interacting with the specific receptor angiotensin-converting enzyme 2 (ACE2; Table I) (7-9), causing clinical symptoms. A retrospective study revealed that COVID-19 may result in multiple clinical symptoms (10). The most common symptoms were determined to be fever (82-98\%), cough (48-92\%), and fatigue/muscle pain (11-75\%), whereas diarrhea (3.7\%) and vomiting $(5.0 \%)$ were less common. Patients with severe infection can exhibit dyspnea and/or hypoxemia, septic shock, acute respiratory distress syndrome, difficult-to-correct metabolic acidosis and coagulation disorders that develop rapidly (11-14). Severe cases have been associated with significant changes in hematological indexes, such as platelet counts, neutrophil/lymphocyte ratio and platelet-to-lymphocyte ratio; these changes may have prognostic value in determining disease severity (15-17). The current treatment strategies for COVID-19 include providing oxygen, mechanical ventilation, intravenous antibiotics and antiviral drugs $(11-14,18)$. However, some severe and critical patients do not respond well to these therapeutic regimens, and there are currently no vaccines against SARS-CoV-2 or specific therapeutic drugs for COVID-19 (11-14). Therefore, timely monitoring of hematological indexes, and further understanding of the mechanisms involved in the development of hematological changes in patients could be helpful in determining prognosis and initiating therapy to improve disease outcomes. 


\section{Hematological changes in patients with COVID-19}

Changes in routine blood tests in patients with COVID-19. Previous studies have reported that patients with SARS and MERS-CoV-infected patients may exhibit some changes in routine blood work, such as lymphopenia, thrombocytopenia and leukopenia $(19,20)$. Similarly, the majority of patients with COVID-19 have been reported to exhibit lymphopenia, and some patients present with thrombocytopenia and leukopenia. Chen et al (12) (n=99) demonstrated that 35, 9 and $24 \%$ of patients with COVID-19 had lymphopenia, leukopenia and high leukocyte counts, respectively. In addition, patients with COVID-19 (38\%) exhibited higher than normal neutrophil counts. Thrombocytopenia and high platelet counts were also observed in 12 and $4 \%$ of patients, respectively, and in 51\% of patients, reduced hemoglobin was detected. Furthermore, a retrospective study $(\mathrm{n}=1,099)$ detected lymphopenia, thrombocytopenia and leukopenia in 82.1, 36.2 and $33.7 \%$ of patients with COVID-19, respectively (14). Different studies have also reported varying rates of lymphopenia and lymphopenia/thrombocytopenia in COVID-19 (13,21-24). Compared with symptoms in non-severe patients, severe patients have been reported to exhibit obvious abnormalities. Wang et al (11) detected progressive lymphopenia in patients with severe COVID-19 (Table II). The platelet-to-lymphocyte ratio is an inflammatory marker that reflects the extent of systemic inflammation and cytokine storms $(15,16)$. Thus, in severe novel $\mathrm{CoV}$ pneumonia cases, dynamic changes in platelet counts and platelet-to-lymphocyte ratios may have significant value in determining disease severity (15-17). In addition to the aforementioned indicators, hypoalbuminemia, $\mathrm{C}$-reactive protein (CRP) and elevated lactate dehydrogenase may be predictors of disease severity. Moreover, in a previous study, the level of angiotensin II in plasma samples from patients with COVID-19 was significantly increased, and was linearly related to viral load and lung injury (21).

Abnormal immune responses in patients with COVID-19. Immune homeostasis is important for eliminating foreign microorganisms and preventing disease in individuals. This balance gets disturbed in patients infected with SARS-CoV-2, and manifests as T-cell depletion and cytokine storms (25). Liu et al $(21)(\mathrm{n}=12)$ reported a decrease in the number of $\mathrm{CD} 8^{+}$ and $\mathrm{CD} 4^{+} \mathrm{T}$ cells in 77.8 and $22.2 \%$ of patients with COVID-19, respectively. In addition, the levels of IL-1 $\beta$, IL-1R $\alpha$, IL-7, IL-8, IL-9, IL-10, granulocyte colony-stimulating factor, granulocyte-macrophage colony-stimulating factor (GM-CSF), IFN- $\gamma$, IFN- $\gamma$-induced protein 10 , monocyte chemoattractant protein 1 (MCP-1), macrophage inflammatory protein (MIP)-1 $\alpha$, MIP-1 $\beta$, platelet-derived growth factor, TNF- $\alpha$ and VEGF were found to be higher in the plasma of infected patients in the intensive care unit (ICU) as compared with those in non-ICU patients (13). The levels of IL-2R and IL-6 have also been reported to be significantly higher in severe cases as compared with those in non-severe patients $(25,26)$ Thus, the depletion of $\mathrm{CD}^{+}$and $\mathrm{CD}^{+} \mathrm{T}$ cells coupled with cytokine storm may be closely related to the progression of COVID-19 $(13,26)$.

Abnormal coagulation in patients with COVID-19. Patients with COVID-19 have been demonstrated to have high coagulation indexes (Table II). In a study comprising individuals with familial aggregation infection $(n=6)$, two patients (33.3\%) had prolonged activated partial thromboplastin time (APTT), two patients (33.3\%) had high levels of plasma D-dimer, and three patients (50\%) had increased fibrinogen content (27).

It has also been demonstrated that $46.4 \%$ of severe patients had high levels of $\mathrm{D}$-dimer $(\mathrm{P}<0.001)(14)$, and increased $\mathrm{D}$-dimers and decreased lymphocytes were found to be associated with disease progression (11). Previous studies have shown that almost all severe patients with COVID-19 have coagulation dysfunction, such as prolongation of prothrombin time (PT) and APTT, an increase in fibrin degradation products and severe thrombocytopenia $(28,29)$. In addition, multiple organ dysfunction caused by disseminated intravascular coagulation has been reported to be an important cause of death in critical patients with COVID-19 $(28,29)$. Therefore, timely monitoring of dynamic blood coagulation functions may aid in the improvement of treatment and prognosis for patients with COVID-19.

\section{Possible mechanisms of lymphopenia and thrombocytopenia in patients with COVID-19}

SARS-CoV-2 attacks hematopoietic cells. It has been shown that plasma from patients with SARS-CoV can inhibit the proliferation and differentiation of colony-forming-unit megakaryocytes (CFU-MK). SARS-CoV has also been reported to infect a small proportion of human MK progenitor cells and $\mathrm{CD}^{+} 4^{+}$hematopoietic stem cells (30). However, the mechanisms involved remain to be explored.

The $\mathrm{S}$ proteins of SARS-CoV-2 and SARS-CoV use a homologous sequence to directly bind ACE2 expressed on $\mathrm{CD}^{+} 4^{+}$hematopoietic stem cells, lymphocytes, monocytes and macrophages (31), in order to initiate infection $(17,32)$. SARS-CoV-2 shares $85 \%$ sequence homology with SARS-CoV. Furthermore, SARS-CoV has similar antigenic characteristics to those of HCoV-229E (31). HCoV-229E uses CD13 to infect monocytes and macrophages, and induce cell apoptosis (33). CD13 is also present on the surface of human bone marrow (BM) $\mathrm{CD}_{34}{ }^{+}$cells, MKs and platelets $(34,35)$. Therefore, CD13 may be a candidate receptor exploited by SARS-CoV to enter blood cells $(33,36,37)$. CoVs can also bind to the CD66a receptor that is expressed on the surface of $\mathrm{CD} 34^{+}$cells, myeloid cells, HL-60 cells, MKs, platelets, T lymphocytes and B lymphocytes (38). Therefore, SARS-CoV-2 may invade hematopoietic stem/progenitor cells, lymphocytes and MKs via ACE2, CD13 or CD66a receptors, thereby resulting in cellular apoptosis, inhibited cell proliferation, lymphopenia and thrombocytopenia.

SARS-CoV-2 has been reported to attack cellular hemoglobin, suggesting the abnormal exchange of oxygen and carbon dioxide in patients (39). The structural proteins of SARS-CoV-2 adhere to heme and form methemoglobin before replacing the resident oxygen and iron, and transforming heme into porphyrin (39). Dissociative iron might induce inflammatory reactions mediated by alveolar macrophages. These and corresponding changes can be detected using computed tomography. Subsequently, SARS-CoV-2 dissociates from oxyhemoglobin, carboxyhemoglobin and glycosylated 
Table I. A list of known human CoVs and their receptors (7-9).

\begin{tabular}{lll}
\hline CoV type & \multicolumn{1}{c}{ Genus } & \multicolumn{1}{c}{ Receptors } \\
\hline HCoV-229E & $\alpha$-coronavirus & hAPN (CD13) \\
HCoV-OC43 & $\beta$-coronavirus & HLA class I \\
HCoV-NL63 & $\alpha$-coronavirus & ACE2 \\
HCoV-HKU1 & $\beta$-coronavirus & Unknown \\
SARS-CoV & $\beta$-coronavirus & ACE2 \\
MERS-CoV & $\beta$-coronavirus & DPP4 (CD26) \\
SARS-CoV-2 & $\beta$-coronavirus & ACE2 \\
\hline
\end{tabular}

$\mathrm{CoV}$, coronavirus; $\mathrm{HCoV}$, human $\mathrm{CoV}$; SARS, severe acute respiratory syndrome; MERS, Middle East respiratory syndrome; hAPN, human aminopeptidase N; ACE2, angiotensin-converting enzyme 2; HLA, human leukocyte antigen; DPP4, dipeptidyl-peptidase 4.

hemoglobin, thereby causing dysfunction in the exchange of oxygen and carbon dioxide in heme. Therefore, SARS-CoV-2 behaves analogous to carbon monoxide in initiating cellular hypoxia and pulmonary embolism (39).

Antibodies and/or immune complexes attack hematopoietic cells. SARS-CoV-2 infection can induce immune responses that result in the production of specific antibodies or immune complexes in patients. Thrombocytopenic patients infected with HIV-1 possess antibodies against platelet proteins that cross-react with HIV-1 glycoprotein 160/120 and elevate the levels of circulating immune complexes $(40,41)$. Subsequently, platelets coated with these antibodies or immune complexes are recognized and destroyed by the reticuloendothelial system. Thus, hematopoietic cells expressing similar antigens can also be injured by the immune complexes. Therefore, antibodies or immune complexes mediate cellular damage and can indirectly induce apoptosis or inhibit the proliferation of hematopoietic stem/progenitor cells, thereby resulting in hemocytopenia (42).

SARS-CoV-2 destroys the hematopoietic microenvironment. The microenvironment in the BM serves an important role in regulating hematopoiesis. BM stromal cells, endothelial cells (ECs), osteoblasts, macrophages, extracellular matrix and secreted cytokines form a honeycomb-like hematopoietic microenvironment $(43,44)$. The destruction and dysfunction of ECs and BM mesenchymal stem cells (MSCs) may alter the hematopoietic microenvironment $(43,45-47)$. The ACE2 receptor is also expressed on the surface of ECs and fibroblasts, and is exploited by SARS-CoV in inducing cellular apoptosis $(48,49)$. As such, EC damage due to the virus binding the ACE2 receptor is possible. Therefore, it may be speculated that SARS-CoV-2 affects the BM microenvironment, including ECs, attenuating hematopoiesis and leading to hemocytopenia.

Drug-induced hematopoietic suppression. Antiviral treatment for COVID-19 includes the use of ribavirin and fluoroquinolones (50). One of the main side effects of these drugs is hematopoietic suppression. Moreover, a previous study has demonstrated that Glucocorticoids as an anti-inflammatory drug can change the circulatory behavior of lymphocytes, particularly $\mathrm{T}$ lymphocytes, thus causing apoptosis of lymphocytes. Therefore, Glucocorticoid-induced lymphopenia may help explain the decreased lymphocyte content in patients with COVID-19 (51).

Thrombocytopenia caused by lung damage. The BM is the primary site of platelet production followed by the lungs (52). MKs in BM cavities migrate and circulate in the blood to the lungs. During pulmonary circulation, platelets are released from MKs in the pulmonary extraneous blood vessels; this accounts for $\sim 50 \%$ of the total platelet population (52). Moreover, blood vessels outside the lung tissue contain mature and immature MKs and hematopoietic progenitors. During thrombocytopenia, there is a reduction in BM-resident stem cells, and these progenitors migrate into the lung and differentiate into different blood cells (52).

Lung injury caused by SARS-CoV-2 can be attributed to the abundant expression of ACE2 on the surface of human alveolar epithelial cells (49). The lungs of patients with COVID-19 exhibit diffuse alveolar damage with pulmonary congestion, edema, formation of a hyaline membrane and fibrosis (53). Extensive alveolar damage reduces the effective capillary bed of the lung, and affects the fragmentation and formation of MKs in pulmonary microcirculation, thereby resulting in thrombocytopenia $(54,55)$. Moreover, virus- or inflammation-induced damage to the hematopoietic progenitors external to the pulmonary vessels may also affect the capacity for migration and differentiation of hematopoietic progenitors in the lung and result in thrombocytopenia (19). Therefore, increased platelet consumption and/or decreased platelet production could directly or indirectly lead to thrombocytopenia.

\section{Possible mechanisms involved in coagulation disorders in patients with COVID-19}

Patients with COVID-19 exhibit varying degrees of coagulation disorders; severity or COVID-19-associated death have been reported to be associated with significant coagulation disorders $(26,28,29)$. Hemostasis involves the regulation of blood vessels and vascular ECs; this requires coordination between normal platelet function, coagulation, anticoagulation and fibrinolysis (56). An imbalance in any of these processes may result in coagulation dysfunction; however, to the best of our knowledge, the mechanism involved in the development of coagulation disorders in patients with COVID-19 remains to be understood.

Cytokine release syndrome (CRS). Interactions between viruses and the host result in activation of the innate and adaptive immune responses in the body. Inactivation or hyperactivation results in a cytokine storm.

In response to $\mathrm{SARS}-\mathrm{CoV}-2$ infection, $\mathrm{CD}^{+} \mathrm{T}$ cells have been reported to be rapidly activated to produce GM-CSF and other inflammatory cytokines. In addition, it has been shown that the SARS-CoV-2 infection of monocytes, macrophages and dendritic cells may result in their activation, and in the secretion of IL-6, TNF- $\alpha$, and MCP-1. These cytokines and chemokines recruit lymphoid cells and myeloid cells, such as 
Table II. Hematological profiles of patients with coronavirus disease-19.

\begin{tabular}{|c|c|c|c|c|c|}
\hline $\begin{array}{l}\text { Authors, year } \\
\text { (patient cohort) }\end{array}$ & $\begin{array}{l}\text { Lymphopenia, } \\
\% \text { of patients }\end{array}$ & $\begin{array}{c}\text { Thrombocytopenia, } \\
\% \text { of patients }\end{array}$ & $\begin{array}{l}\text { Leukopenia, } \\
\% \text { of patients }\end{array}$ & $\begin{array}{l}\text { High D-dimer, } \\
\% \text { of patients }\end{array}$ & (Refs.) \\
\hline Guan and Zhong $(\mathrm{n}=1,099)$ & 82.1 & 36.2 & 33.7 & 46.4 & (14) \\
\hline Chen et al $(\mathrm{n}=99)$ & 35.0 & 12.0 & 9.0 & 36 & (12) \\
\hline Liu et al $(\mathrm{n}=137)$ & 72.3 & NA & 37.2 & NA & $(10)$ \\
\hline Huang et al $(\mathrm{n}=41)$ & 63.0 & 5.0 & 25.0 & NA & (13) \\
\hline Chen et al $(\mathrm{n}=29)$ & 69.0 & 17.0 & 21.0 & NA & (26) \\
\hline Liu et al $(\mathrm{n}=12)$ & 54.5 & 8.3 & 0.0 & NA & $(21)$ \\
\hline Chan et al $(\mathrm{n}=6)$ & NA & 28.6 & 28.6 & 66.7 & (27) \\
\hline
\end{tabular}

NA, not applicable.

activated $\mathrm{T}$ cells and macrophages (57-59). Cells continue to be activated and expand, releasing inflammatory mediators; however, the overwhelming release of inflammatory factors not only recruits more immune cells, but also damages the homeostasis of the immune system and the function of normal cells, resulting in a cytokine storm (57-59).

Direct virus infection and uncontrolled inflammation can cause damage to the microvascular system, destroying the integrity of the vascular EC barrier, and resulting in the reduction of platelet EC adhesion molecule-1 (PECAM-1) on the cell surface and an increase in plasma soluble PECAM-1 (60,61). Moreover, EC damage may lead to the overexpression of tissue factor (TF), thereby activating the exogenous coagulation system, while inhibiting anticoagulation and fibrinolysis, among other processes, leading to DIC (50). The excessive inflammatory response in DIC and the destruction of the EC barrier promote each other, forming a feedback loop, which may eventually lead to systemic microvascular thrombosis, increased platelet consumption, massive consumption of coagulation factors and secondary hyperfibrinolysis, manifested as microcirculation disorders and bleeding (50). Moreover, IL-6 has an important role in the network of inflammatory mediators. It can cause coagulation disorders through various pathways, such as stimulating the liver to synthesize more thrombopoietin and fibrinogen, among others, and upregulating the expression of VEGF to destroy the stability of the vascular barrier, which stimulates monocytes to express more tissue factors and exacerbates activation of the exogenous coagulation system $(50,58)$. The generated thrombin in turn can induce vascular endothelium to produce more IL- 6 and other cytokines. Storms and coagulation disorders thus form a vicious circle $(50,58)$.

Liver damage. Increased levels of glutamic-pyruvic transaminase and glutamic oxaloacetic transaminase, and decreased levels of albumin, have been detected in patients with COVID-19 $(13,14)$. These findings suggest the development of liver dysfunction induced by SARS-CoV-2 and a reduction in the synthesis of clotting factors, ultimately causing coagulation disorders. Moreover, coagulation dysfunction can be caused by the use of antiviral drugs, such as ribavirin, which is associated with hepatotoxicity, and the reduced synthesis of coagulation factors and other molecules $(50,62)$.

Ischemic hypoxic reperfusion injury or attack of ECs by $S A R S-C o V-2$. Ischemic hypoxic reperfusion injury can trigger oxidative stress in ECs, thus increasing the production of superoxide and decreasing the production of nitric oxide. This results in EC damage, exposure of TF on the outer membrane of vascular cells and the activation of exogenous coagulation pathways (50). SARS-CoV-2 may also aggravate damage to ECs by directly binding to ACE2 on their surfaces. The expression of TF on the cell surface increases upon EC damage. This causes damage to antithrombin III, TF pathway inhibitor and protein $\mathrm{C}$, as well as the loss of anticoagulant properties. EC damage also leads to an imbalance in fibrinolysis, resulting in coagulation dysfunction (50).

Cardiopulmonary bypass pipes and improper use of blood products have also been reported to cause abnormal coagulation (50). Coagulation disorders can appear at any stage of COVID-19 and can worsen with disease progression. Therefore, the timely monitoring of blood coagulation may help improve treatment and prognosis for patients with COVID-19.

\section{Potential treatments}

The treatment strategies currently used for COVID-19 include providing oxygen, mechanical ventilation, intravenous antibiotics, antiviral drugs and some traditional Chinese medicines. Patients with severe infection and symptoms are subjected to mechanical ventilation; however, the efficacy of non-invasive ventilation is limited due to the development of hypoxia in patients with COVID-19 (14,50). Therefore, the transfusion of plasma from convalescent patients, blood-purifying therapy and immune therapy may help treat severe or critical patients.

Chloroquine is a widely used antimalarial drug, which has been reported to have potential therapeutic effects on various viral diseases (such as HIV-1/AIDS and SARS) $(63,64)$. Chloroquine blocks viral infections by increasing endosomal $\mathrm{pH}$, interfering with virus/cell binding and interfering with the glycosylation of SARS-CoV cell receptors (65). Wang et al (66) reported chloroquine to be highly effective 
in the control of SARS-CoV-2 infection in vitro. Moreover, Gao et al (67) conducted clinical trials on 100 patients with COVID-19 infection. The results suggested that chloroquine had a significant effect in terms of viral clearance and clinical outcomes compared with those in the control groups. Therefore, the use of chloroquine may improve the prognosis of patients with COVID-19 and could be considered an effective treatment.

Hydroxychloroquine and chloroquine have similar chemical structures and cellular mechanisms of action (68). Gautret et al (69) performed a clinical trial study and indicated that hydroxychloroquine was associated with viral decrease and disappearance in patients with COVID-19. Moreover, Zhou et al (70) demonstrated that hydroxychloroquine may provide better results than chloroquine for the treatment of SARS-CoV-2 infection. Indeed, hydroxychloroquine can attenuate the severe progression of COVID-19, inhibiting the cytokine storm by suppressing $\mathrm{T}$ cell activation. In addition, it has fewer side effects and is safe in pregnancy . Based on these findings, it was hypothesized that hydroxychloroquine may be more effective than chloroquine in treating patients with COVID-19.

Radecivir has a structure similar to adenosine and exhibits broad-spectrum antiviral activity against RNA viruses (71). Notably, it has been reported to have antiviral activity against various CoVs, including SARS-CoV and MERS-CoV, in vitro and in vivo (72,73). Radecivir has been reported to lead to the premature termination of viral RNA chains by inhibiting RNA-dependent RNA polymerase, consequently halting replication of the viral genome (74). In a recent in vitro study, remdesivir was found to effectively inhibit SARS-CoV-2 (67). Moreover, the first case report of a patient with COVID-19 in the USA indicated that the use of redoxivir could improve their condition (increased oxygen saturation values, improved appetite and reduced cough symptoms) (75). Remdesivir is currently undergoing multiple trials in different countries, including two randomized phase III trials in China (NCT04252664 and NCT04257656).

Glycyrrhizic acid and MSCs have immunoregulatory and anti-inflammatory functions (76-78). The antiviral activity of ribavirin, 6-azapyrimidine, pyrazolofuran, mycophenolic acid and glycyrrhizin has been shown based on two clinically isolated CoVs (FFM-1 and FFM-2) from patients with SARS included in the Frankfurt University Clinical Center (79). Glycyrrhizin has been reported to be more efficient in inhibiting the replication of SARS-associated viruses, compared with ribavirin, 6-azauridine, pyrazofurin and mycophenolic acid (79). Furthermore, a clinical trial revealed that MSCs may have significant effects on COVID-19, such as decreasing CRP levels, improving lung symptoms and significantly improving lymphopenia (80). Therefore, glycyrrhizic acid and MSCs may prevent or reduce excessive cytokine storms and improve prognosis in patients with COVID-19.

In addition, a clinical trial revealed that ruxolitinib could improve clinical symptoms by reducing cytokine storms (81). Notably, it is clear that there are currently no drugs available that specifically target SARS-CoV-2. The primary focus is on symptomatic treatment and preventing complications. In addition, the diagnosis and treatment of COVID-19 during its early stages may significantly reduce mortality.

\section{Conclusions}

In conclusion, COVID-19 causes lung damage and multiple systemic changes in patients, especially in the hematological system. In the early stages, patients present with lymphopenia. Patients develop thrombocytopenia, coagulation disorders and CRS in the later stage of disease, which can lead to DIC and multiple organ failure. Thus, hematological changes are of critical importance for patients with COVID-19. However, the relevant mechanisms are still unclear. Based on the existing clinical findings and the experience during SARS, research on the underlying mechanisms may help to improve the diagnosis, treatment and prognosis of patients with COVID-19.

\section{Acknowledgements}

Not applicable.

\section{Funding}

This work was supported by the National Natural Science Foundation of China (grant no. 81770116 to MY) and the Natural Science Foundation of Guangdong Province (grant no. 2017A030313767 to JYY).

\section{Availability of data and materials}

Not applicable.

\section{Authors' contributions}

JY, YJ, YZ, MY wrote the manuscript. ZL designed Table I and XZ designed Table II. HD collected relevant literature. JY and MY revised and commented on the mansucript. All authors read and approved the final manuscript.

\section{Ethics approval and consent to participate}

Not applicable.

\section{Patient consent for publication}

Not applicable.

\section{Competing interests}

The authors declare that they have no competing interests.

\section{References}

1. Lu H, Stratton CW and Tang YW: Outbreak of pneumonia of unknown etiology in Wuhan, China: The mystery and the miracle. J Med Virol 92: 401-402, 2020.

2. Wang $X$, Zhang $X$ and He J: Challenges to the system of reserve medical supplies for public health emergencies: Reflections on the outbreak of the severe acute respiratory syndrome coronavirus 2 (SARS-CoV-2) epidemic in China. Biosci Trends 14: 3-8, 2020.

3. Zhu N, Zhang D, Wang W, Li X, Yang B, Song J, Zhao X, Huang B, Shi W, Lu R, et al: A novel coronavirus from patients with pneumonia in China, 2019. N Engl J Med 382: 727-733, 2020.

4. Bogoch II, Watts A, Thomas-Bachli A, Huber C, Kraemer MUG and Khan K: Potential for global spread of a novel coronavirus from China. J Travel Med 27: taaa011, 2020. 
5. Corman VM, Lienau J and Witzenrath $\mathrm{M}$ : Coronaviruses as the cause of respiratory infections. Internist (Berl) 60: 1136-1145, 2019 (In German).

6. Grifoni A, Sidney J, Zhang Y, Scheuermann RH, Peters B and Sette A: A sequence homology and bioinformatic approach can predict candidate targets for immune responses to SARS-CoV-2. Cell Host Microbe 27: 671-680.e2, 2020.

7. Ksiazek TG,Erdman D, Goldsmith CS, Zaki SR, Peret T,Emery S, Tong S, Urbani C, Comer JA, Lim W, et al: A Novel Coronavirus Associated with Severe Acute Respiratory Syndrome. N Engl J Med 348: 1953-1966, 2003.

8. Reguera J, Mudgal G, Santiago C and Casasnovas JM: A structural view of coronavirus-receptor interactions. Virus Res 94 $3-15,2014$

9. Huang X, Dong W, Milewska A, Golda A, Qi Y, Zhu QK Marasco WA, Baric RS, Sims AC, Pyrc K, et al: Human coronavirus HKU1 spike protein uses O-Acetylated sialic acid as an attachment receptor determinant and employs hemagglutinin-esterase protein as a receptor-destroying enzyme. J Virol 89: 7202-7213, 2015.

10. Liu K, Fang YY, Deng Y, Liu W, Wang MF, Ma JP, Xiao W, Wang YN, Zhong MH, Li CH, et al: Clinical characteristics of novel coronavirus cases in tertiary hospitals in Hubei Province. Chin Med J (Engl) 133: 1025-1031, 2020.

11. Wang D, Hu B, Hu C, Zhu F, Liu X, Zhang J, Wang B, Xiang H, Cheng Z, Xiong Y, et al: Clinical characteristics of 138 hospitalized patients with 2019 novel coronavirus-infected pneumonia in Wuhan, China. JAMA 323: 1061-1069, 2020.

12. Chen N, Zhou M, Dong X, Qu J, Gong F, Han Y, Qiu Y, Wang J, Liu Y, Wei Y, et al: Epidemiological and clinical characteristics of 99 cases of 2019 novel coronavirus pneumonia in Wuhan, China: A descriptive study. Lancet 395: 507-513, 2020.

13. Huang C, Wang Y, Li X, Ren L, Zhao J, Hu Y, Zhang L, Fan G, $\mathrm{Xu}$ J, Gu X, et al: Clinical features of patients infected with 2019 novel coronavirus in Wuhan, China. Lancet 395: 497-506, 2020.

14. Guan WJ and Zhong NS: Clinical characteristics of Covid-19 in China. Reply. N Engl J Me 382: 1861-1862, 2020.

15. Qu R, Ling Y, Zhang YH, Wei LY, Chen X, Li XM, Liu XY, Liu HM, Guo Z, Ren H and Wang Q: Platelet-to-lymphocyte ratio is associated with prognosis in patients with coronavirus disease-19. J Med Virol: Mar 17:10.1002/jmv.25767, 2020.

16. Gasparyan AY, Ayvazyan L, Mukanova U, Yessirkepov M and Kitas GD: The platelet-to-lymphocyte ratio as an inflammatory marker in rheumatic diseases. Ann Lab Med 39: 345-357, 2019.

17. Terpos E, Ntanasis-Stathopoulos I, Elalamy I, Kastritis E, Sergentanis TN, Politou M, Psaltopoulou T, Gerotziafas G and Dimopoulos MA: Hematological findings and complications of COVID-19. Am J Hematol 95: 834-847, 2020.

18. Singhal T: A review of coronavirus disease-2019 (COVID-19). Indian J Pediatr 87: 281-286, 2020

19. Yang M, Hon KL, Li K, Fok TF and Li CK: The effect of SARS coronavirus on blood system: Its clinical findings and the pathophysiologic hypothesis. Zhongguo Shi Yan Xue Ye Xue Za Zhi 11: 217-221, 2003

20. Al-Tawfiq JA, Hinedi K, Abbasi S, Babiker M, Sunji A and Eltigani M: Hematologic, hepatic, and renal function changes in hospitalized patients with Middle East respiratory syndrome coronavirus. Int J Lab Hematol 39: 272-278, 2017.

21. Liu Y, Yang Y, Zhang C, Huang F, Wang F, Yuan J, Wang Z, Li J, Li J, Feng C, et al: Clinical and biochemical indexes from 2019-nCoV infected patients linked to viral loads and lung injury. Sci China Life Sci 63: 364-374, 2020.

22. Guan WJ, Ni ZY, Hu Y, Liang WH, Ou CQ, He JX, Liu L, Shan H, Lei CL, Hui DSC, et al: Clinical characteristics of coronavirus disease 2019 in China. N Engl J Med 382: 1708-1720, 2020

23. Zhou F, Yu T, Du R, Fan G, Liu Y, Liu Z, Xiang J, Wang Y, Song B, Gu X, et al: Clinical course and risk factors for mortality of adult inpatients with COVID-19 in Wuhan, China: A retrospective cohort study. Lancet 395: 1054-1062, 2020.

24. Lippi G, Plebani M and Henry BM: Thrombocytopenia is associated with severe coronavirus disease 2019 (COVID-19) infections: A meta-analysis. Clin Chim Acta 506: 145-148, 2020.

25. Li G, Fan Y, Lai Y, Han T, Li Z, Zhou P, Pan P, Wang W, Hu D, Liu $\mathrm{X}$, et al: Coronavirus infections and immune responses. J Med Virol 92: 424-432, 2020.

26. Chen L, Liu HG, Liu W, Liu J, Liu K, Shang J, Deng Y and Wei S: Analysis of clinical features of 29 patients with 2019 novel coronavirus pneumonia. Zhonghua Jie He He Hu Xi Za Zhi 43: E005, 2020 (In Chinese)
27. Chan JF, Yuan S, Kok KH, To KK, Chu H, Yang J, Xing F, Liu J, Yip CC, Poon RW, et al: A familial cluster of pneumonia associated with the 2019 novel coronavirus indicating person-to-person transmission: A study of a family cluster. Lancet 395: 514-523, 2020

28. Guan W, Ni Z, Hu Y, Liang W, Ou C, He J, Liu L, Shan H, Lei CL, Hui DSC, et al: Clinical characteristics of 2019 novel coronavirus infection in China. medRxiv: Jan 1;2020.02.06.20020974, 2020

29. Arachchillage DRJ and Laffan M: Abnormal coagulation parameters are associated with poor prognosis in patients with novel coronavirus pneumonia. J Thromb Haemost 18: 1233-1234, 2020

30. Yang M, Ng MH, Li CK, Chan PKS, Liu C, Ye JY and Chong BH: Thrombopoietin levels increased in patients with severe acute respiratory syndrome. Thromb Res 122: 473-477, 2008.

31. Chan JF, Kok KH, Zhu Z, Chu H, To KK, Yuan S and Yuen KY: Genomic characterization of the 2019 novel human-pathogenic coronavirus isolated from a patient with atypical pneumonia after visiting Wuhan. Emerg Microbes Infect 9: 221-236, 2020.

32. Xu H, Zhong L, Deng J, Peng J, Dan H, Zeng X, Li T and Chen Q High expression of ACE2 receptor of $2019-\mathrm{nCoV}$ on the epithelial cells of oral mucosa. Int J Oral Sci 12: 8, 2020.

33. Collins AR: In vitro detection of apoptosis in monocytes/macrophages infected with human coronavirus. Clin Diagn Lab Immunol 9: 1392-1395, 2002

34. Yang M, Li K, Chui CMY, Yuen PMP, Chan PK, Chuen CK, Li CK and Fok TF: Expression of interleukin (IL) 1 type I and type II receptors in megakaryocytic cells and enhancing effects of IL-1beta on megakaryocytopoiesis and NF-E2 expression. $\mathrm{Br}$ J Haematol 111: 371-380, 2000.

35. Yang M, Khachigian LM, Hicks C, Chesterman $\mathrm{CN}$ and Chong BH: Identification of PDGF receptors on human megakaryocytes and megakaryocytic cell lines. Thromb Haemost 78: 892-896, 1997.

36. Kontoyiannis DP, Pasqualini R and Arap W: Aminopeptidase N inhibitors and SARS. Lancet 361: 1558, 2003

37. Wentworth DE and Holmes KV: Molecular determinants of species specificity in the coronavirus receptor aminopeptidase N (CD13): Influence of N-linked glycosylation. J Virol 75: 9741-9752, 2001

38. Hammarström S: The carcinoembryonic antigen (CEA) family: Structures, suggested functions and expression in normal and malignant tissues. Semin Cancer Biol 9: 67-81, 1999.

39. Liu W and Li H: COVID-19: Attacks the 1-beta chain of hemoglobin and captures the porphyrin to inhibit human heme metabolism. ChemRxiv, 2020.

40. Scaradavou A: HIV-related thrombocytopenia. Blood Rev 16: 73-76, 2002.

41. Nardi M, Tomlinson S, Greco MA and Karpatkin S: Complement-independent, peroxide-induced antibody lysis of platelets in HIV-1-related immune thrombocytopenia. Cell 106: 551-561, 2001.

42. Yang M, Li CK, Li K, Hon KL, Ng MH, Chan PK and Fok TF: Hematological findings in SARS patients and possible mechanisms (review). Int J Mol Med 14: 311-315, 2004.

43. Taichman RS: Blood and bone: Two tissues whose fates are intertwined to create the hematopoietic stem-cell niche. Blood 105: 2631-2639, 2005.

44. Ru YX, Dong SX, Zhao SX, Li Y, Liang HY, Zhang MMF, Zhu X and Zheng Y: One cell one niche: Hematopoietic microenvironments constructed by bone marrow stromal cells with fibroblastic and histiocytic features. Ultrastruct Pathol 43: 117-125, 2019.

45. Lord BI: The architecture of bone marrow cell populations. Int J Cell Cloning 331: 317-331, 1990.

46. Kiel MJ, Yilmaz ÖH, Iwashita T, Yilmaz OH, Terhorst $\mathrm{C}$ and Morrison SJ: SLAM family receptors distinguish hematopoietic stem and progenitor cells and reveal endothelial niches for stem cells. Cell 121: 1109-1121, 2005.

47. Sugiyama T, Kohara H, Noda M and Nagasawa T: Maintenance of the hematopoietic stem cell pool by CXCL12-CXCR4 chemokine signaling in bone marrow stromal cell niches. Immunity 25 : 977-988, 2006

48. Hamming I, Timens W, Bulthuis ML, Lely AT, Navis GJ and van Goor H: Tissue distribution of ACE2 protein, the functional receptor for SARS coronavirus. A first step in understanding SARS pathogenesis. J Pathol 203: 631-637, 2004.

49. Ye J, Zhang B, Xu J, Chang Q, McNutt MA, Korteweg C, Gong E and $\mathrm{Gu} \mathrm{J}$ : Molecular pathology in the lungs of severe acute respiratory syndrome patients. Am J Pathol 170: 538-545, 2007.

50. Mei $\mathrm{H}$ and $\mathrm{Hu} \mathrm{Y}$ : Characteristics, causes, diagnosis and treatment of coagulation dysfunction in patients with COVID-19. Zhonghua Xue Ye Xue Za Zhi 41: 185-191, 2020 (In Chinese). 
51. Panesar NS: What caused lymphopenia in SARS and how reliable is the lymphokine status in glucocorticoid-treated patients? Med Hypotheses 71: 298-301, 2008.

52. Lefrançais E, Ortiz-Muñoz G, Caudrillier A, Mallavia B, Liu F, Sayah DM, Thornton EE, Headley MB, David T, Coughlin SR, et al: The lung is a site of platelet biogenesis and a reservoir for haematopoietic progenitors. Nature 544: 105-109, 2017.

53. Xu Z, Shi L, Wang Y, Zhang J, Huang L, Zhang C, Liu S, Zhao P, Liu H, Zhu L, et al: Pathological findings of COVID-19 associated with acute respiratory distress syndrome. Lancet Respir Med 8: 420-422, 2020.

54. Niinikoski J, Goldstein R, Linsey $M$ and Hunt TK: Effect of oxygen-induced lung damage on tissue oxygen supply. Acta Chir Scand 139: 591-595, 1973.

55. Yang M, Ng MH and Li CK: Thrombocytopenia in patients with severe acute respiratory syndrome (review). Hematology 10 : 101-105, 2005

56. LeVine DN, Cianciolo RE, Linder KE, Bizikova $\mathrm{P}$ Birkenheuer AJ, Brooks MB, Salous AK, Nordone SK, Bellinger DA, Marr H, et al: Endothelial alterations in a canine model of immune thrombocytopenia. Platelets 30: 88-97, 2019.

57. Zhou Y, Fu B, Zheng X, Wang D, Zhao C, Qi Y, Sun R, Tian Z, $\mathrm{Xu} \mathrm{X}$ and Wei H: Aberrant pathogenic GM-CSF${ }^{+} \mathrm{T}$ cells and inflammatory $\mathrm{CD} 14^{+} \mathrm{CD} 16^{+}$monocytes in severe pulmonary syndrome patients of a new coronavirus. bioRxiv: Feb 20, 2020 (Epub ahead of print). doi: 10.1101/2020.02.12.945576.

58. Moore BJ and June $\mathrm{CH}$ : Cytokine release syndrome in severe COVID-19. Science 368: 473-474, 2020.

59. Hirano T and Murakami M: COVID-19: A new virus, but a familiar receptor and cytokine release syndrome. Immunity 52 731-733, 2020

60. Cohen J: The immunopathogenesis of sepsis. Nature 420: $885-891,2002$

61. Goldbergers A, Middletons KA, Oliver JA, Paddock C, Yan H, Delissero HM, Albelda SM and Newman PJ: Biosynthesis and processing of the cell adhesion molecule PECAM-1 includes production of a soluble form. J Biol Chem 269: 17183-17191, 1994.

62. Chaves J, Huen A, Bueso-Ramos C, Safdar A and Vadhan-Raj S: Aerosolized Ribavirin-induced reversible hepatotoxicity in a hematopoietic stem cell transplant recipient with Hodgkin lymphoma. Clin Infect Dis 42: e72-e75, 2006.

63. Savarino A, Di Trani L, Donatelli I, Cauda Rand Cassone A New insights into the antiviral effects of chloroquine. Lancet Infect Dis 6: 67-69, 2006.

64. Yan Y, Zou Z, Sun Y, Li X, Xu KF, Wei Y, Jin N and Jiang C: Anti-malaria drug chloroquine is highly effective in treating avian influenza A H5N1 virus infection in an animal model. Cell Res 23: 300-302, 2013.

65. Vincent MJ, Bergeron E, Benjannet S, Erickson BR, Rollin PE, Ksiazek TG, Seidah NG and Nichol ST: Chloroquine is a potent inhibitor of SARS coronavirus infection and spread. Virol J 2: 69, 2005.

66. Wang M, Cao R, Zhang L, Yang X, Liu J, Xu M, Shi Z, Hu Z, Zhong W and Xiao G: Remdesivir and chloroquine effectively inhibit the recently emerged novel coronavirus $(2019-\mathrm{nCoV})$ in vitro. Cell Res 30: 269-271, 2020.

67. Gao J, Tian Z and Yang X: Breakthrough: Chloroquine phosphate has shown apparent efficacy in treatment of COVID-19 associated pneumonia in clinical studies. Biosci Trends 14: 72-73, 2020.
68. Liu J, Cao R, Xu M, Wang X, Zhang H, Hu H, Li Y, Hu Z, Zhong $\mathrm{W}$ and Wang $\mathrm{M}$ : Hydroxychloroquine, a less toxic derivative of chloroquine, is effective in inhibiting SARS-CoV-2 infection in vitro. Cell Discov 6: 16, 2020.

69. Gautret P, Lagier JC, Parola P, Hoang VT, Meddeb L, Mailhe M, Doudier B, Courjon J, Giordanengo V, Vieira VE, et al: Hydroxychloroquine and azithromycin as a treatment of COVID-19: Results of an open-label non-randomized clinical trial. Int J Antimicrob Agents 56: 105949, 2020.

70. Zhou D, Dai SM and Tong Q: COVID-19: A recommendation to examine the effect of hydroxychloroquine in preventing infection and progression. J Antimicrob Chemother 75: 1667-1670, 2020.

71. Siegel D, Hui HC, Doerffler E, Clarke MO, Chun K, Zhang L, Neville S, Carra E, Lew W, Ross B, et al: Discovery and synthesis of a phosphoramidate prodrug of a Pyrrolo[2,1-f][triazin-4-amino] adenine C-nucleoside (GS-5734) for the treatment of ebola and emerging viruses. J Med Chem 60: 1648-1661, 2017.

72. Sheahan TP, Sims AC, Graham RL, Menachery VD, Gralinski LE, Case JB, Leist SR, Pyrc K, Feng JY, Trantcheva I, et al: Broad-spectrum antiviral GS-5734 inhibits both epidemic and zoonotic coronaviruses. Sci Transl Med 9: eaal3653, 2017.

73. Agostini ML, Andres EL, Sims AC, Graham RL, Sheahan TP, Lu X, Smith EC, Case JB, Feng JY, Jordan R, et al: Coronavirus susceptibility to the antiviral remdesivir (GS-5734) is mediated by the viral polymerase and the proofreading exoribonuclease. mBio 9: e00221-18, 2018

74. Mulangu S, Dodd LE, Davey RT Jr, Tshiani Mbaya O, Proschan M, Mukadi D, Lusakibanza Manzo M, Nzolo D, Tshomba Oloma A Ibanda A, et al: A randomized, controlled trial of ebola virus disease therapeutics. N Engl J Med 381: 2293-2303, 2019.

75. Holshue ML, DeBolt C, Lindquist S, Lofy KH, Wiesman J, Bruce H, Spitters C, Ericson K, Wilkerson S, Tural A, et al: First case of 2019 novel coronavirus in the United States. N Engl J Med 382: 929-936, 2020.

76. Akutagawa K, Fujita T, Ouhara K, Takemura T, Tari M, Kajiya M, Matsuda S, Kuramitsu S, Mizuno N, Shiba H and Kurihara H: Glycyrrhizic acid suppresses inflammation and reduces the increased glucose levels induced by the combination of Porphyromonas gulae and ligature placement in diabetic model mice. Int Immunopharmacol 68: 30-38, 2019.

77. Yan S, Fang C, Cao L, Wang L, Du J, Sun Y, Tong X, Lu Y and Wu X: Protective effect of glycyrrhizic acid on cerebral ischemia/reperfusion injury via inhibiting HMGB1-mediated TLR4/NF- $\kappa$ B pathway. Biotechnol Appl Biochem 66: 1024-1030, 2019.

78. Chen S, Cui G, Peng C, Lavin MF, Sun X, Zhang E, Yang Y, Guan Y, Du Z and Shao H: Transplantation of adipose-derived mesenchymal stem cells attenuates pulmonary fibrosis of silicosis via anti-inflammatory and anti-apoptosis effects in rats. Stem Cell Res Ther 9: 110, 2018.

79. Cinatl J, Morgenstern B, Bauer G, Chandra P, Rabenau H and Doerr HW: Glycyrrhizin, an active component of liquorice roots, and replication of SARS-associated coronavirus. Lancet 361: 2045-2046, 2003.

80. Leng Z, Zhu R, Hou W, Feng Y, Yang Y, Han Q, Shan G, Meng F, Du D, Wang S, et al: Transplantation of ACE2(-) mesenchymal stem cells improves the outcome of patients with COVID-19 pneumonia. Aging Dis 11: 216-228, 2020.

81. Cao Y, Wei J, Zou L, Jiang T, Wang G, Chen L, Huang L, Meng F, Huang L, Wang N, et al: Ruxolitinib in treatment of severe coronavirus disease 2019 (COVID-19): A multicenter, single-blind, randomized controlled trial. J Allergy Clin Immunol 146: 137-146.e3, 2020. 